\title{
Internal Consistency Reliability of Career Decision Making Difficulty Questionnaire
}

\author{
Priscilla Manuel $^{1 *}$, Dr. P. Mahendran ${ }^{2}$
}

\section{ABSTRACT}

The purpose of the present study was to test the internal consistency of Career Decision Making Difficulty Questionnaire (CDDQ) developed by Itamar Gati and Samuel H. Osipow (2010) among student population in India. Two hundred students studying in 7 schools and 1 college in Coimbatore city completed the Career Decision Difficulty Questionnaire between the age group of 14 to 20 years. The responses were collected and the data was subjected to statistical analysis to test internal consistency. The Cronbach's and Spearman Brown Coefficient value shows high reliability. The results indicated CDDQ as a reliable instrument for assessing career decision making difficulties among the students of Indian population. Further study among student population in other states of India is recommended for validation.

Keywords: Career Decision Making Difficulty, Reliability, Students

Career is the vital aspect of human life. In the global scenario, the youth of today are experiencing wide range of career opportunities in India. There exist a broad scope of exploring new jobs emerging with rapid growth of science and technology. The career that was considered as most significant in earlier days is becoming less popular due to advancements in the field of education. The courses offered by the educational institutes have wide options that enable the adolescents to explore, learn, think and invent. It becomes important that the adolescents need to make the right career choice for a fulfilling career life. Hence there is a deep sense of urgency to educate and to equip the younger generation to adapt to the career choices of the new era. Hence making the right career decision has become the need of the hour.

According to Kelly \& Lee (2002), the domain of career decision problem has not been adequately explored. It is noted that nearly $40 \%$ of youth are not aware of where they need to seek help in their decision making and 38\% state that they need to go to many places to get information and trustworthiness of information sources is of high relevance (Julien, 2004). The

\footnotetext{
${ }^{1}$ Research Scholar, Department of Psychology, PSG College of Arts \& Science, Coimbatore

${ }^{2}$ Associate Professor \& Head, Department of Psychology, PSG College of Arts \& Science, Coimbatore *Responding Author

(C) 2016 I P Manuel, P Mahendran; licensee IJIP. This is an Open Access Research distributed under the terms of the Creative Commons Attribution License (http://creativecommons.org/licenses/by/2.0), which permits unrestricted use, distribution, and reproduction in any Medium, provided the original work is properly cited.
} 
information on career opportunities with more clarity needs to be implemented at educational institutions. The choice of career is a most crucial challenge among among students as students were not aware of realistic type of careers where they use hands, tools and machines and they lack self knowledge on career interests (Sikhwari, 2015). In a study on the effectiveness of sources of support in career decision making among university students, 65\% indicated difficult to choose a field of study and 46\% stated they intended to seek help. (Vertsberger \& Gati, 2015). There exists a direct relationship between decidedness and subjective well being and hence career interventions should aim at increasing decidedness among the first year college students. (Uthayakumar, Schimmack, 2010).

As Career undecided adolescents exhibited poorer career, well being and social outcomes than the decided students (Creed, Prideaux, 2004). It is noted that various factors influence the career decision making of adolescents in India. The socio economic background and social cognitive environments influence career development in India with lower socio economic status groups showing higher level of negative career beliefs (Arulmani, Larr, Easton, 2003). Career choice is also influenced by skills, competencies and abilities as the most important factor and "father" was the most significant among management Indian students (Agarwala, 2008). According to Gokuladas, (2010) the decisions of engineering students first career choices are influenced by intrinsic than extrinsic reasons with male students influenced by intrinsic reasons and female students by extrinsic reasons. Therefore there is a need to identify the Career Decision Making Difficulty and the present study aims to validate the questionnaire on Career Decision Making Difficulty (Gati and Osipow, 2010) to student population in India.

Career counsellors should attend to the challenges students face in relation to making career decisions so as to reduce their level of indecision. The graduate students are inadequately prepared for career due to lack of knowledge on the graduate labour market as they show reluctance to use formal sources of information as university career service. Hence counselors need to address the negative career thoughts among college students encountering career and life stress as increase in negative career thinking resulted in lower level of decidedness and satisfaction with career choice. (Yowell, Peterson, Readrdon, Leierer, Reed, 2011).The career services need to encourage students to reflect on how to undertake career decision making and planning.

\section{METHOD}

The present study aims to test the internal consistency of Career Decision Making Difficulty Questionnaire (CDDQ) among school and college students in India.

The 34 item Career Decision Making Difficulty Questionnaire developed by Itamar Gati and Samuel H. Osipow (2010). The rationale underlying the taxonomy of CDDQ was proposed by Gati, Krausz, and Osipow (1996). 
The taxonomy of Career Decision Making Difficulty Questionnaire was proposed by Gati, Krausz and Osipow (1996) based on the decision making and information processing theories. The CDDQ involves assessing Career Decision Making Difficulty based on two distinctions. The first distinction is between difficulties arising before beginning the career decision making process as difficulties involving a lack of readiness and the second distinction are those that arise during the process as lack of information and difficulties in utilizing the information due to information consistency.

The study involves random sampling technique that comprised of 200 samples representing from 7 schools and 1 college between the age group of 14 to 20 years with the mean age as 17.9 years. $15 \%$ in the age group of $14-15$ years, $18.5 \%$ in the age group of $16-17$ years, $39.5 \%$ in the age group of $18-19$ years and $27 \%$ in the age group of 20 years. Boys represent $59 \%$ and girls represent $41 \%$ in the representative sample.

\section{Procedure:}

The study was conducted in three sessions among school children and college students. In the first session, 50 school children were the samples and were administered the Career Decision Making Difficulty Questionnaire. Session two was conducted among 50 college students and session three among 100 college students. The instructions were given in each session to respond to the statement that best describes them. The samples responded to the 34 items in the printed format questionnaire by reading each statement and responding by putting a circle mark corresponding to the statement that applies to them. The responses were collected and the data was subjected to statistical analysis.

\section{RESULTS}

To examine the reliability of Career Decision Making Difficulty Questionnaire (CDDQ,) the Spearman Brown Coefficient and Cronbach's Alpha among student population in India was analyzed.

The results for the present study are depicted in the table given below:

\begin{tabular}{|l|l|l|}
\hline Method & Nos. & ' $\mathbf{r}$ ' \\
\hline Cronbach's Alpha & 17 items (Part 1\# ) & .749 \\
\cline { 2 - 3 } & 17 items (Part 2 \#) & .890 \\
\hline Correlation between forms & & .723 \\
\hline Spearman-Brown Coefficient & Equal length & $.839^{*}$ \\
\cline { 2 - 3 } & Unequal length & $.839^{*}$ \\
\hline Guttman-Split Half Coefficient & & .820 \\
\hline
\end{tabular}

\# Part 1: Questions from 1 to 17 \# Part 2: Questions from 18 to 34

The Cronbach's alpha value is found to be .74 for part 1 set of items (17 nos.) and .89 for part 2 set of items (17 nos.) The Cronbach's Alpha reliability coefficient normally ranges between 0 
and 1. The present values of .74 and .89 indicate good internal consistency reliability. There exists a good correlation between the two sets of items as the correlation value is found to be .72 . The Spearman-Brown Coefficient value of equal and unequal length represents .839 and the Guttman Split half coefficient is .820 pointing that Career Decision Making Difficulty Questionnaire has high internal consistency reliability. Career Decision Making Difficulty Questionnaire is a reliable instrument that can be administered among Indian population.

\section{LIMITATION}

The study was limited to 4 schools and 1 residential college in Coimbatore city. Hence the results obtained cannot be generalized to the entire population.

\section{CONCLUSION}

The study shows that Career Decision Making Difficulty Questionnaire is a reliable tool that can be used among student population in India. Further studies are needed to confirm the use of CDDQ among various student populations located in different states in India.

\section{REFERENCES}

Agarwala, T. (2008). Factors influencing career choice of management students in India. Career Development International, 13(4), 362-376.

Arulmani, G., Van Laar, D., \& Easton, S. (2003). The influence of career beliefs and socioeconomic status on the career decision-making of high school students in India. International Journal for Educational and Vocational Guidance, 3(3), 193-204.

Bullock-Yowell, E., Peterson, G. W., Reardon, R. C., Leierer, S. J., \& Reed, C. A. (2011). Relationships among career and life stress, negative career thoughts, and career decision state: A cognitive information processing perspective. The career development quarterly, 59(4), 302-314.

Gokuladas, V. K. (2010). Factors that influence first-career choice of undergraduate engineers in software services companies: A south Indian experience. Career development international, 15(2), 144-165.

Julien, H. (2004). Adolescent decision-making for careers: An exploration of information behavior. Youth information-seeking behavior: Theories, models, and issues, 321À352.

Kelly, K. R., \& Lee, W. C. (2002). Mapping the domain of career decision problems. Journal of Vocational Behavior, 61(2), 302-326.

Sikhwari, T. D. (2015). Investigating first Year Students’ Abilities to Make Appropriate Career Choices.

Skorikov, V. (2007). Continuity in adolescent career preparation and its effects on adjustment. Journal of Vocational Behavior, 70(1), 8-24.

Uthayakumar, R., Schimmack, U., Hartung, P. J., \& Rogers, J. R. (2010). Career decidedness as a predictor of subjective well-being. Journal of Vocational Behavior, 77(2), 196-204.

Vertsberger, D., \& Gati, I. (2015). The effectiveness of sources of support in career decisionmaking: A two-year follow-up. Journal of Vocational Behavior, 89, 151-161. 